\title{
Neonatal Seizures: Correlation between Clinico-Etiological Profile and EEG Findings
}

\author{
RUMAPARVIN ${ }^{1}$ AFMSALIM ${ }^{2}$, MIZANUR RAHMAN ${ }^{3}$, KONA CHOWDHURY $^{4}$, AZMERI SULTANA $^{1}$, SHAFI \\ AHMED $^{5}$, K. M. ZIAUR RAHMAN ${ }^{6}$
}

\begin{abstract}
:
Introduction: Seizures are quite common in newborn babies. Among other investigations, EEG is used to show the type and location of the activity in the brain during a seizure. Correlation between clinico-etiological profile of neonatal seizures and EEG findings, so far, has not been studied in Bangladesh.
\end{abstract}

Objective: The objective of the study was to correlate the clinical, etiological and EEG profile of neonatal seizures.

\begin{abstract}
Methodology: It was a cross-sectional study done at NICU of BSMMU and Central Hospital Ltd. All the neonates admitted with seizures during the study period were included in the study. Their clinico-etiological profiles were carefully recorded and EEG were done in all the cases. Chi-square test was done to find out the statistical difference.
\end{abstract}

Results: Among total 51 cases of neonatal seizures, 29 (56.86\%) cases had perinatal asphyxia, followed by septicemia in 8 (15.67\%) and meningitis in 6 (11.76\%). Hypoglycemia and hypocalcaemia was found in 10 (19.6\%) \& 8 (15.7\%) cases respectively and $15(29.4 \%)$ had acidosis . Thirty seven (72.5\%) patients had seizure within $3^{\text {rd }}$ day of life. Seizures were found tonic in nature in 23(45.1\%) cases and subtle 18 (35.3\%) cases. EEG findings were abnormal in $22(43.1 \%)$ cases. EEG findings were analyzed with the etiology of seizures and it was found that there was a significant relationship between EEG changes and perinatal asphyxia $(p<.0001)$, septicemia $(p<.05)$, meningitis $(p<.01)$ and neurometabolic disorder $(p<.0001)$. However, no statistical significant relationship between type of discharges of EEG and type ( $p>.05)$ \& pattern of seizures ( $p>.05)$ was found.

Conclusion: This study suggests that there is a significant statistical relationship between EEG findings with perinatal asphyxia, septicemia and meningitis, but no relationship with types and pattern of seizures.

\section{Introduction:}

Neonatal seizures are the most common neurological problems in the newborn. ${ }^{1}$ Determining the underlying etiology for neonatal seizures is critical. Etiology determines prognosis and outcome and guides therapeutic strategies. $^{2}$

Seizures in neonates are different from those seen in older children. The differences are perhaps due to

1. Assistant Professor, Institute of Child Health \& Shishu Sasthya Foundation Hospital.

2. Professor of Paediatrics, Institute of Child Health \& Shishu Sasthya Foundation Hospital.

3. Professor and Head, Dept. of Paediatric Neurology, BSMMU.

4. Assistant Professor, Dept. of Paediatrics, Ad-din Women's Medical College and Hospital.

5. Assistant Professor, Dept. of Paediatrics, Northern International Medical College, Dhaka.

6. Resident, Dept. of Neurosurgery, Holy Family Red Crescent Medical College and Hospital.

Correspondence: Dr. Ruma Parvin : 01711119127 the neuro-anatomic and neurophysiologic developmental status of the newborn infant. In the neonatal brain glial proliferation, neuronal migration, establishment of axonal deposition, dendritic contacts and myelin deposition are incomplete. For these reasons, clinical presentation differs. ${ }^{3}$

Hypoxic-ischemic encephalopathy (HIE) is an important cause of neonatal seizures. A detailed pregnancy history, history of TORCH (toxoplasmosis, rubella, cytomegalovirus, herpes) infections, fetal distress, pre-eclampsia, or maternal infection also can provide etiologic clues. Neonatal seizures with an uneventful antenatal history and delivery may result from a postnatal cause. A history of tremulousness may suggest drug withdrawal or neonatal hypocalcaemia. $^{4}$ 
EEG is valuable in confirming the presence of seizures. The EEG findings, such as background abnormality, area of involvement of the discharges and the type of discharges were seen to categorize the neonatal seizures. In neonatal seizures, EEG amplitudes are usually low (bilateral cortical damage, wide spread cerebral damage, structural brain stem damage, mild metabolic disorders etc.) or very low (extensive cortical damage due to any cause). Slow waves in EEG in neonatal seizures signify any type of anoxic, metabolic, toxic encephalopathy etc. The clinical observation of the neonate with suspected seizures is often inadequate, if we are to characterize and understand the nature of the epileptic and non-epileptic events that are occurring.

The aim of the study was, therefore, to determine and correlate the etiological factors, clinical types and EEG profile of neonatal seizures.

\section{Methodology:}

This cross-sectional study was carried out in the Neonatology Department of Bangabandhu Sheikh Mujib Medical University (BSMMU) and Neonatal Intensive Care Unit of Central Hospital Limited. Total study period was six months commencing from $1^{\text {st }}$ September 2010 to $28^{\text {th }}$ February 2011.

Fifty one neonates with seizures admitted into the neonatology unit of BSMMU and Central Hospital during the study period were enrolled in the study.

\section{Selection criteria of the study population}

Inclusion criteria: All the neonates admitted in the hospital during the study period with clinically identified seizures.

\section{Exclusion criteria:}

1. Newborns with gross congenital anomalies.

2. Extreme prematures (Birth weight $<1000 \mathrm{gms}$ )

3. Babies on ventilators right from the begin of admission.

Extreme premature and babies on ventilators were excluded deliberately, because in all the cases, EEG was recorded in the EEG Lab. Transferring these critical babies to the EEG Lab was technically not possible in these cases.

\section{Methodology}

All the neonates admitted with seizures during the study period were included in the study. Detailed history regarding age, sex, gestational age, maternal history of pregnancy, perinatal and history of birth asphyxia, time of occurrence and types of seizure, history of fever, lethargy or reluctance to feed etc. were taken and carefully recorded by the study physician. EEG was done in all the cases when stable, but not later than 7 days of occurrence of seizure. EEG was done using standard methods and standard number of leads as is done in all cases of neonatal seizures in our settings. Serum calcium and glucose levels were measured using standard methods in a compatible biochemical laboratory. For data analysis, SPSS version 16.0 for windows was used. Ethical clearance was obtained according to the rules of BCPS.

\section{Results:}

A total of 51 neonates having various types of seizures were studied during the study period. The mean age of the neonates was $8.84 \pm 7.17$ days (Range 1-12 days). 76.5 (39/51) were male and $23.5 \%(12 / 51)$ were female. Fifty two point nine four percent $(27 / 51)$ were delivered at term and $56.86 \%(29 / 51)$ had perinatal asphyxia, followed by septicemia $15.67 \%$ ( $8 / 51)$, meningitis $11.76 \%$ ( 6/51), neonatal jaundice $3.92 \%(2 / 51)$, neurometabolic disorder 3.92\%(2/51), and TORCH (Rubella) infection 1.96\%(1/51). Seizures were found tonic in nature $45.1 \%(23 / 51)$ cases followed by subtle $35.3 \%(18 / 51)$, clonic $15.7 \%(8 /$ 51)and mixed 3.9\%(2/51)cases(Table 1). Hypoglycemia and hypocalcaemia was found in $19.6 \%$ $(10 / 51)$ and $15.65 \%(8 / 51)$ cases respectively and $29.4 \%(15 / 51)$ had acidosis. Majority i.e, $72.5 \%$ ( $37 /$ $51)$ patients had seizure within $3^{\text {rd }}$ day of life. There was $1.96 \%(1 / 51)$ neonate where definite diagnosis could not be established. Electroencephalography (EEG) was done in all cases within 7 days of occurrence of seizure, but when stable. Among these, $43.1 \%(22 / 51)$ cases were found and in majority of the cases i.e., 56.9\% (29/51) had normal EEG findings (Table 6). EEG findings were analyzed with the etiology of seizures and it was found that there was a significant relationship between EEG changes and perinatal asphyxia $(p<.0001)$, septicemia $(p<.05)$, meningitis $(p<.01)$ and neurometabolic disorder $(p<.0001)$ (TableIII-IV). However, no statistical significant relationship between type of discharges of EEG and type ( $p>.05)$ $\&$ pattern of seizures ( $p>05$ ) was found(Table-V).

Table-I

Showing type of seizure among the study neonates. $(n=51)$

\begin{tabular}{lcc}
\hline Type of seizure & Frequency & Percent \\
\hline Tonic & 23 & 45.1 \\
Subtle & 18 & 35.3 \\
Clonic & 8 & 15.7 \\
Mixed & 2 & 3.9 \\
\hline Total & 51 & 100.0 \\
\hline
\end{tabular}


Table-II

Showing the EEG findings among the study neonates. $(n=51)$

\begin{tabular}{lcclcclcc}
\hline \multicolumn{3}{c}{$\begin{array}{l}\text { Background abnormality } \\
\end{array}$} & \multicolumn{2}{c}{ Area of involvement of discharges } & \multicolumn{3}{c}{ Type of discharges } \\
& Frequency & Percent & & Frequency & Percent & Frequency & Percent \\
\hline Low voltage & 12 & 23.5 & Generalized & 4 & 7.8 & Spikes & 6 & 11.8 \\
Very low voltage & 4 & 7.8 & Multifocal & 2 & 3.9 & Sharp spikes & 8 & 15.7 \\
Slow waves & 6 & 11.8 & Focal & 16 & 31.4 & Both & 2 & 3.9 \\
\hline Total & 22 & 43.1 & Total & 22 & 43.1 & Total & 16 & 31.4 \\
\hline
\end{tabular}

Table shows the EEG findings of the neonate, including background abnormality, area of involvement of the discharges and the type of discharges. In background abnormality $23.5 \%$ had low voltage. In area of involvement of the discharges, it was mostly focal (31.4\%). In type discharges, sharp spikes (15.7\%) were predominant, followed by spikes (11.8\%).

Table-III

Association of the EEG findings and the perinatal asphyxia of the neonate.

\begin{tabular}{lcccr}
\hline EEG & H/O perinatal asphyxia & $\chi^{2}$ & P value \\
findings & No & Yes & & $<.0001$ \\
\hline Normal & 14 & 10 & & \\
Abnormal & 8 & 19 & 15.013 & $<.0001$ \\
\hline Total & 22 & 29 & & \\
\hline
\end{tabular}

Table shows that there was a statistically significant relationship between EEG findings and the perinatal asphyxia $\left(\chi^{2}=15.013, \mathrm{df}=1, \mathrm{p}<.0001\right)$. The other abnormal EEG findings in different groups were statistically not significant (not shown in the table).

\section{Table - IV}

Association between background abnormality of EEG and meningitis of the neonate.

\begin{tabular}{|c|c|c|c|c|c|}
\hline \multirow{2}{*}{$\begin{array}{l}\text { Background } \\
\text { abnormality }\end{array}$} & \multicolumn{2}{|c|}{ Meningitis } & \multirow[t]{2}{*}{ Total } & \multirow[t]{2}{*}{$\chi^{2}$} & \multirow{2}{*}{$\begin{array}{c}\mathrm{P} \\
\text { value }\end{array}$} \\
\hline & No & Yes & & & \\
\hline Low voltage & 0 & 12 & 12 & & \\
\hline Very low voltage & 2 & 2 & 04 & 10.236 & .006 \\
\hline slow waves & 4 & 2 & 06 & & \\
\hline Total & 06 & 16 & 22 & & \\
\hline
\end{tabular}

Table shows that majority i.e. $72.7 \%$ ( 16 out of 22 ) with abnormal EEG findings were suffering from meningitis and this relationship was statistically significant $\left(x^{2}=5.346, d f=2, p<.01\right)$.
Table-V

Association between type of discharges of EEG and of seizure of the neonate.

\begin{tabular}{|c|c|c|c|c|c|}
\hline \multirow{2}{*}{$\begin{array}{l}\text { Type of } \\
\text { discharges }\end{array}$} & \multicolumn{3}{|c|}{ Type of seizure } & \multirow[t]{2}{*}{ Total } & \multirow{2}{*}{$\begin{array}{c}\mathrm{P} \\
\text { value }\end{array}$} \\
\hline & Subtle & Mixe & Ionic & & \\
\hline Spikes & 2 & 2 & 2 & 6 & \\
\hline Sharp spikes & 4 & 4 & 0 & 8 & .216 \\
\hline Both & 2 & 0 & 0 & 2 & \\
\hline Total & 8 & 6 & 2 & 16 & \\
\hline
\end{tabular}

Table shows there was no statistically significant relationship between type of discharges of EEG and type of $\operatorname{seizures}\left(\chi^{2}=5.778, \mathrm{df}=4, \mathrm{p}>.05\right)$.

Table-VI

Distribution of the child by the EEG findings.

\begin{tabular}{lcc}
\hline EEG Findings & Frequency & Percent \\
\hline Normal & 29 & 56.9 \\
Abnormal & 22 & 43.1 \\
\hline Total & 51 & 100 \\
\hline
\end{tabular}

\section{Discussion}

Seizures in neonatal life are quite common. EEG is not done in all cases, and if done, the relationship between EEG findings and neonatal seizures is usually not analyzed with due importance. In this study, we have observed 51 neonates with seizures over a period of 6 months, and the EEG findings in these cases were analyzed.

In the present study, 39 cases $(76.5 \%)$ were male and the rest $12(23.5 \%)$ were female with a male to female ratio of $3.25: 1$. These findings were consistent with previous studies, where male predominant was found. 5,6 Our study, 37(72.5\%) neonates had H/O onset of seizure within 3 days of life. In a study of neonatal seizures by Ronen et al, onset of seizures 
on first day of life was 36\%; $64 \%$ had onset of seizures within first 48 hours, and $83 \%$ within first week of life, which is similar to our study. In the study. Of Volpe j, however, seizures most commonly occurred prior to 24 hours of age and approximately $50 \%$ occurred within initial 12 hours $^{8}$, which is consistent with this study.

In this study four fifth of the baby were delivered at term (80.4\%), only one fifth were preterm birth (19.6\%) and average birth weight of the neonate was 2591.84 $\pm 536.27 \mathrm{gm}$. Similar observations were documented by Sandhu et al, ${ }^{9}$ where term AGA neonate were $81.2 \%$ followed by preterm neonate in $18.8 \%$. In our study, half of the neonate had perinatal asphyxia (56.86\%), followed by septicemia (15.67\%), meningitis (11.76\%), neonatal jaundice (kernicterus) (3.92\%), neurometabolic disorder (3.92\%), TORCH (Rubella infection 1.96\%). There were $1.96 \%$ neonates whom diagnosis could not be identified. Thirty five neonates had biochemical abnormalities and most of them had hypoglycemia (19.5\%) and hypocalcaemia (15.7\%). About $29.4 \%$ suffered from acidosis. There were no hypernatremia or hyperglycemia. Birth asphyxia was also the commonest cause of neonatal seizures reported by Soni et al ${ }^{10}$ and Ronen et al. ${ }^{7}$ In a study of neonatal seizures by Arthur $\mathrm{L}$ et al, ${ }^{11}$ majority of neonates with perinatal asphyxia $50 \%$, hypoglycemia $71 \%$, CNS infection $69 \%$, and hypocalcaemia during first and second day of life (6/28) and again during late first week and second week (19/28). Our findings were consistent with these studies.

We found majority of seizures was tonic $(45.1 \%)$ in nature, followed by subtle seizure (35.3\%), clonic (15.35) and mixed type (3.9\%). In most of the cases seizures was generalized (62.7\%) followed by focal (17.65\%) and mixed (19.61\%) type respectively. In a study of neonatal seizures by Brunquell $\mathrm{J}$ et al ${ }^{12}$ subtle seizures were the commonest occurring in 51\% (27 of 53), followed by focal clonic (42\%), multifocal clonic (30\%) and GTS (23\%). Lakra et al ${ }^{5}$ also reported that subtle seizures were the commonest type. But in the study of Soni et al, ${ }^{10}$ generalized tonic seizure was commonest type of seizure, followed by subtle seizures.

In our study, about half (43.1\%) of the EEG findings were abnormal. In background abnormality, $23.5 \%$ had low voltage; very low voltage was in $11.8 \%$. In area of involvement of the discharges, it was mostly focal (31.4\%). In the type of discharges, sharp spikes
(15.7\%) and spikes (11.8\%) were predominant. There was a statistically significant relationship between EEG findings and the perinatal asphyxia of the neonates $(\div 2=15.013, d f=1, p<.000)$. Rose and Lombroso $^{12}$ and Mizarahi and Kellaway ${ }^{13}$ reported abnormalities in standard EEG in HIE in $70 \%$ and $46.3 \%$ cases respectively.

In this study, there was a statistically significant relationship of meningitis with background abnormality of EEG (low voltage recorded in 12 cases, very low voltage recorded \& slow wave voltage recorded in 2 cases each), area of involvement of discharges of EEG (focal in 14 cases, generalized in 2 cases), and type of discharges (spike in 6 cases, sharp spike in 2 cases). There was also a statistically significant relationship of septicemia with background abnormality of EEG (very low voltage in 2 cases, low voltage and slow wave 6 cases in each), area of involvement of discharges of EEG (focal in 12 cases and multifocal in 2 cases). Abnormal standard EEGs in meningitis with or without other sepsis (not separated by authors) has also been reported in 33.3\% cases by Rose and Lombroso ${ }^{12}$ and $17 \%$ by Mizrahi and kellaway ${ }^{14}$ which were consistent with our study.

\section{Conclusion}

Most common cause of neonatal seizure is perinatal asphyxia. Acidosis is most common biochemical change associated with neonatal seizure. Tonic and subtle seizure was found as common seizure type in neonatal seizure. Significant relationship was found EEG recording with perinatal asphyxia, septicemia and meningitis. EEG findings were found normal in majority of cases of neonatal seizure.

\section{References:}

1. Silverstein FS, Jensen FE. Neonatal seizures. Ann Neurol 2007; 62:112-20.

2. Volpe JJ. Hypoxic-Ischemic Encephalopathy: Biochemical and Physiological Aspects. In: Neurology of the Newborn. $4^{\text {th }}$ ed. Philadelphia: WB Saunders; 2000: 217-76.

3. Rose AL, Lombroso CT. A study of clinical, pathological, and electroencephalographic features in 137 full-term babies with neonatal seizures. Pediatrics. 1970 Mar; 45: 404-25.

4. Volpe J J. Neonatal Seizures. Neurology of the new born. 4th ed. Philadelphia: W.B. Saunders. 2001:178-216. 
5. Lakra Mahaveer, Vilhekar KY, Chaturvedi Pushpa.Clinico-biochemical profile of neonatal seizures in a rural medical college. In: Fernandez AIH, Dadhich JPP, Saluja Y'S, Editors, Abstracts, XXIII Annual Convention of National Neonatology Fornum, Dec. 18-21, 2003; Hydrabad. 2003: 121-22.

6. Freeman John M. Neonatal seizures-Diagnosis and Management. J Pediatr, Oct. 1970; 77 : 7018.

7. Ronen Gabriel M, Penny Sharon RN, Andrews S Wayne. The Epidemiology of Clinical Neonatal Seizures in Newfound Land: A Population-Based Study. J Pediatr, Jan 1999; 134: 71-75.

8. Volpe JJ. Neurology of the newborn. Philadelphia: WB Saunders Company, 1987: 129-58.

9. Sandhu Ravneet. A clinical study of seizures in neonates. In: Shah NKH, Agrawal R, Yewale V, editors. Abstracts XXXX National Conference of the Indian Academy of Pediatrics, $2^{\text {nd }}$ to $5^{\text {th }}$ Jan; 2003: Mumbai; 2003: 209-10.

10. Soni Arun. Clinical profile of seizures in neonatal intensive care unit. In: Fernandez AH, Dadhich JPP, Saluja Y'S, Editors, Abstracts, XXIII Annual. Convention of National Neonatology Forum, Dec. 18-21, 2003; Hyderabad. 2003: 109-11.

11. Rose AL, Lombroso CT. Neonatal seizure status: A Study of Clinical, Pathological and Electroencephalographic features in137 Full Term Babies with a Long Term Follow Up. Pediatrics 1970; 45 : 404-25.

12. Brunquell PJ, Glennon CM, DiMario FJ Jr, Lerer T, Eisenfeld L. Prediction of Outcome Based on Clinical Seizures Type in Newborn Infants. J Pediatr. 2002 Jun;140:707-12.

13. Mizrahi EM, Kellaway P. Characterization Classification of Neonatal Seizure. Neurology 1987; 37: 1837-44. 